\title{
Endoscopic submucosal dissection using an SB Knife Jr. with clip traction method for esophageal cancer at the anastomotic site after total gastrectomy
}

Endoscopic submucosal dissection (ESD) enables the operator to achieve R0 resection regardless of the tumor size. However, ESD for lesions with severe fibrosis remains technically challenging. Here, we describe a patient who under- went successful ESD of an esophageal cancer using the Stag Beetle (SB) Knife $\mathrm{J}$. with the clip traction method.

A 70-year-old woman was referred to our hospital for treatment of esophageal cancer. She had undergone total gas-
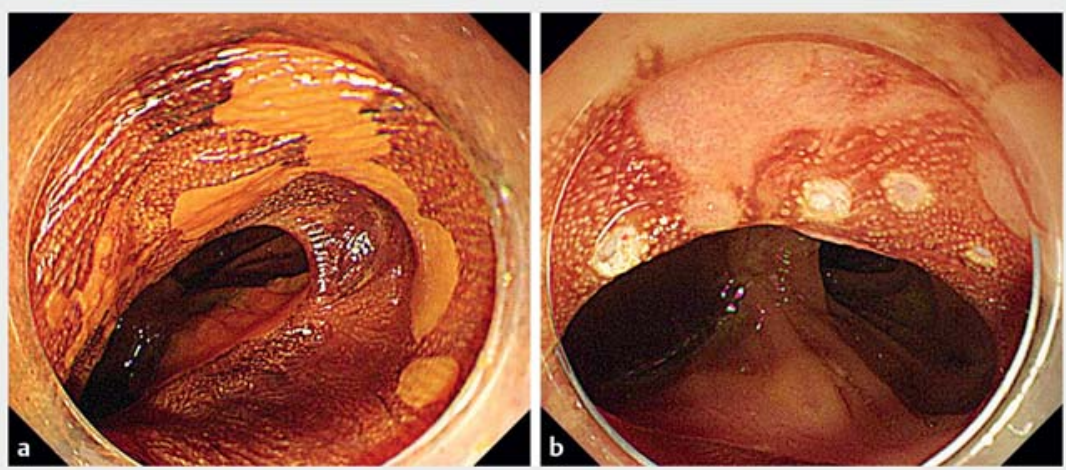

- Fig. 1 Endoscopic view showing a flat lesion located at the site of the anastomosis after total gastrectomy that was extending around half the circumference of the esophagus: a before marking; $\mathbf{b}$ after marking.

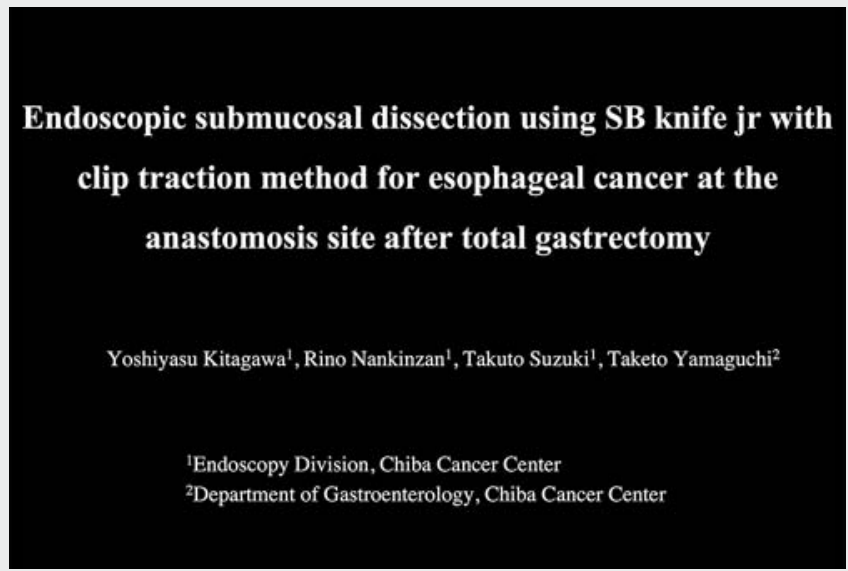

Video 1 Endoscopic submucosal dissection for esophageal cancer at the anastomotic site after total gastrectomy: circumferential incisions are made at the oral then anal sides (a surgical staple is found in the incision line); the clip traction method is used and the submucosa is dissected using an SB Knife Jr. first from the oral side, then from the anal side. Despite severe fibrosis being present in the submucosal layer at the anastomotic site, en bloc resection was achieved without injury to the muscularis propria. trectomy for advanced gastric cancer at another hospital 2 years previously. Endoscopy revealed a flat lesion involving half the circumference of the esophagus. This lesion was located at the site of the anastomosis from the total gastrectomy ( $\triangleright$ Fig. 1 ).

Circumferential incisions were created using a DualKnife (Olympus, Tokyo, Japan) and the SB Knife Jr. (Sumitomo Bakelite, Tokyo, Japan) [1]. During incision at the anastomotic site, we encountered several surgical staples ( $\mathbf{F i g} \cdot \mathbf{2}$ a). After the circumferential incisions had been made, a clip with thread was anchored to the oral edge of the specimen [2,3]. The line was pulled through the mouth to provide traction. As expected, severe fibrosis was encountered in the submucosal layer at the anastomotic site, so we carefully dissected the site using the SB Knife Jr. ( $\triangleright$ Fig. 2 b). Finally, en bloc resection was achieved without injury to the muscularis propria ( Video 1 ). Next, triamcinolone acetonide was injected into the residual submucosal layer after completion of the resection [4].

Histological examination revealed a squamous cell carcinoma with microinvasion of the lamina propria mucosae, showing free lateral and deep margins (\$ Fig.3). Follow-up endoscopy after 2 months revealed no evidence of a postoperative stricture ( $\triangleright$ Fig. 4).

Esophageal ESD using the SB Knife Jr. with the clip traction method was particularly useful for safe dissection at the anastomotic site. We suggest the use of this technique for the treatment of difficult lesions with severe fibrosis.

Endoscopy_UCTN_Code_TTT_1AO_2AG 


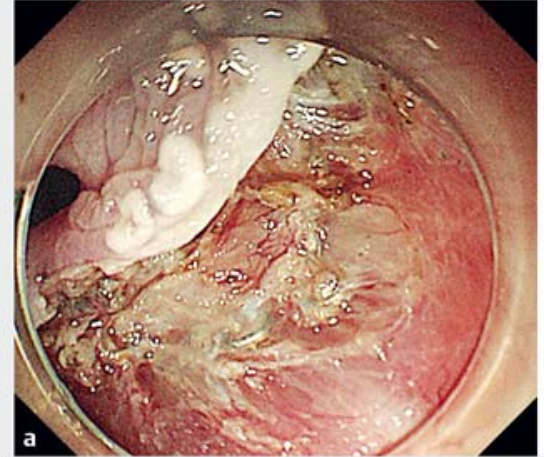

- Fig. 2 Endoscopic views during endoscopic submucosal dissection showing: a a surgical staple remaining in the incision line; $\mathbf{b}$ severe fibrosis in the submucosal layer at the anastomotic site.

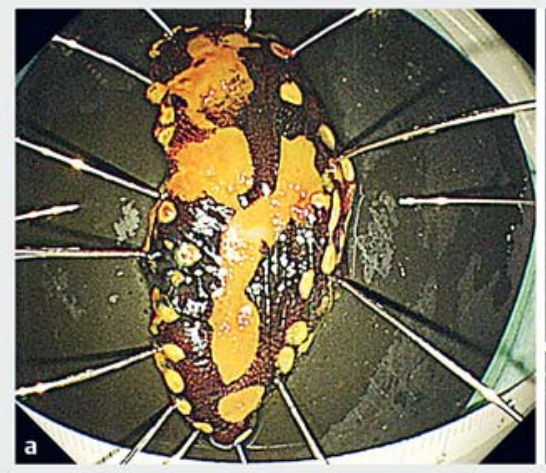

- Fig. 3 The resected specimen after iodine staining, which was subsequently shown to be an esophageal squamous cell carcinoma.

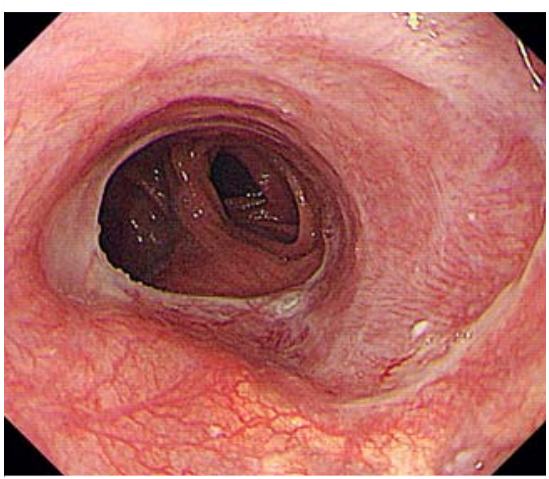

Fig. 4 Follow-up endoscopy 2 months later showing no postoperative stricture.
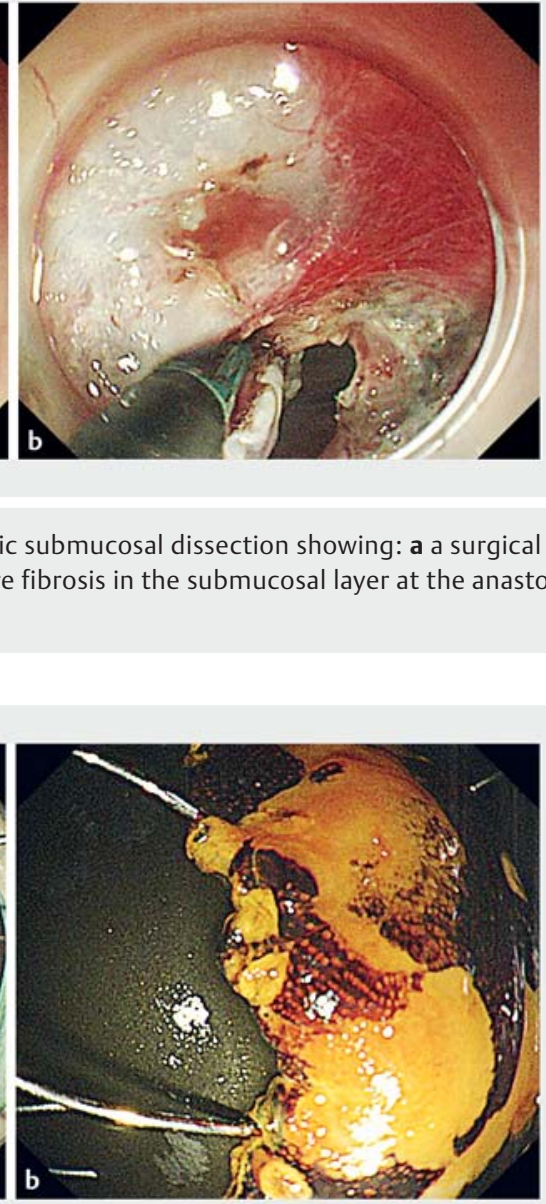

Corresponding author

\section{Yoshiyasu Kitagawa, MD}

Endoscopy Division, Chiba Cancer Center, 666-2 Nitonacho, Chuo-ku, Chiba, Japan

Fax: +39-043-2628680

ykitagawa@chiba-cc.jp

\section{References}

[1] Homma K, Otaki Y, Sugawara M et al. Efficacy of novel SB knife Jr examined in a multicenter study on colorectal endoscopic submucosal dissection. Dig Endosc 2012; 24: $117-120$

[2] Oyama T. Countertraction makes endoscopic submucosal dissection easier. Clin Endosc 2012; 45: 375-378

[3] Kitagawa Y, Suzuki T, Hara T et al. Safety and efficacy of endoscopic submucosal dissection using IT knife nano with clip traction method for early esophageal squamous cell carcinoma. Surg Endosc 2018; 32: 450-455

[4] Hashimoto S, Kobayashi M, Takeuchi M et al. The efficacy of endoscopic triamcinolone injection for the prevention of esophageal stricture after endoscopic submucosal dissection. Gastrointest Endosc 2011; 74 : $1389-1393$

\section{Bibliography}

DOI https://doi.org/10.1055/a-0866-9250

Published online: 25.3.2019

Endoscopy 2019; 51: E143-E144

(c) Georg Thieme Verlag KG

Stuttgart · New York

ISSN 0013-726X

Competing interests

None

The authors

Yoshiyasu Kitagawa', Rino Nankinzan' ${ }^{1}$, Takuto Suzuki ${ }^{1}$, Taketo Yamaguchi ${ }^{2}$

1 Endoscopy Division, Chiba Cancer Center, Chiba, Japan

2 Department of Gastroenterology, Chiba Cancer Center, Chiba, Japan

\section{ENDOSCOPY E-VIDEOS \\ https://eref.thieme.de/e-videos}

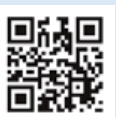

Endoscopy E-Videos is a free access online section, reporting on interesting cases and new

techniques in gastroenterological endoscopy. All papers include a high quality video and all contributions are freely accessible online.

This section has its own submission website at

https://mc.manuscriptcentral.com/e-videos 